\title{
Technetium Tc 99m-labeled Tilmanocept
}

National Cancer Institute

\section{Source}

National Cancer Institute. Technetium Tc 99m-labeled Tilmanocept. NCI Thesaurus.

Code $C 77898$.

A radiolabeled macromolecule consisting of the chelating agent diethylenetriamine pentaacetic acid (DTPA) and mannose each attached to a dextran backbone and labeled with metastable technetiumT c-99 (Tc-99m), with mannose binding and radioisotopic activities. Upon injection, the mannose moiety of technetium Tc 99m-labeled tilmanocept binds to mannose-binding protein (MBP). As MBPs reside on the surface of dendritic cells and macrophages, this gamma-emitting macromolecule tends to accumulate in lymphatic tissue where it may be imaged using gamma scintigraphy. This agent exhibits rapid clearance from the injection site, rapid uptake and high retention within the first draining lymph node, and low uptake by the remaining lymph nodes. MBP is a C-type lectin that binds mannose or fucose carbohydrate residues, such as those found on the surfaces of many pathiogens, and once bound activates the complement system. 